\title{
Effects of authentic leadership on organizational citizen behaviors of employees -- with workplace spirituality as a mediator
}

\author{
Ke Jianglin ${ }^{1}$, Zheng Lujian ${ }^{1}$, Yuan Dongxue ${ }^{2}$ \\ 1.Beijing Normal University No. 19, XinJieKouWai St., HaiDian District, Beijing China \\ 2. BMW China Automotive Trading Ltd. \\ Gateway Piaza,No.18 XiaGuangLi,East 3rd Ring North Rd.,ChaoYang District, Beijing China \\ kejianglin@126.com; bnuzlj@126.com; 18811476879@163.com
}

Keywords: Authentic leader; Workplace spirituality; Organizational citizen behaviors

\begin{abstract}
Authentic leadership and workplace spirituality are two novel concepts emerging in the field of management, and considerably contribute to leadership revolution and intra-organizational management. Employees, as the most basic and important part of an enterprise, play a non-negligible role in the organization. Organizational citizen behaviors, the behaviors beyond the contract that are conducted due to personal willingness, can significantly promote the organizational development and enlargement. In this study, we explored the relationships among authentic leadership, workplace spirituality and organizational citizen behaviors. It was validated the authentic leadership of direct leaders could promote the formation of organizational citizen behaviors among employees, and the workplace spirituality of senior employees would stimulate the conduction of more organizational citizen behaviors. Moreover, the workplace spirituality of employees plays a significant mediating role between their organizational citizen behaviors and the authentic leadership of direct leaders. Therefore, more attention should be paid to the adjustment and transition of leader patterns and the inner spirituality of employees during modern management practices.
\end{abstract}

\section{Introduction}

\subsection{Background}

The frequently-occurring manager-level scandals and malpractice from Shanghai Brightdairy, Samsung and other corporations in recent years have alerted people that aestheticism is the guarantee for the survival and development of enterprises. Meanwhile, growing attention has been paid to the theories and empirical research of authentic leadership. Authentic leadership would affect individuals, teams and organizations (Illies, 2005). Authentic leadership can be used to predict the organizational citizen behaviors of employees (Deng et al., 2012), which generally can improve organizational performance (Organ, 1983), further proving the importance of authentic leadership. However, there is rare research on the mechanism how authentic leadership affects the organizational citizen behaviors of employees.

According to the theory of social exchange, all social activities of leaders and employees in an enterprise can be defined as exchange activities. Liden \& Graen (1980) think the leader-employee exchange relationship involves some social exchanges that are beyond the requirements of employment contracts and are built upon the mutual trust between leaders and employees. The concept of authentic leadership covers four dimensions: self-awareness, internalized moral, balanced processing, and relational transparency (Walumbwa, 2008), and authentic leaders are more likely to generate high-quality social exchange with the employees. The theory of social cognition holds that cognitive factors play important roles in behavior alteration, and that individuals, behaviors and the environment are mutually influential, dependent and decisive (Bandura, 1977). 
The authentic leadership directly affects the cognition and behaviors of employees. Workplace spirituality is an inner self-cognition that supports meaningful works under the collectiveness background and is cultivated by the meaningful works. This novel concept in the field of management is a spiritual driving force for employees and differs from other concepts of organization commitment, organization identification, and psychological capital. Workplace spirituality is associated with many factors, so it is urgent to explore its relationship with organizational citizen behaviors, which are manifested as individual behaviors, but act on the organization. Therefore, in this study, we discussed and validated the relationships among authentic leadership, workplace spirituality and organizational citizen behaviors.

1.2 Theories and hypotheses

Authentic leadership is a novel theory in the field of leadership. Burns (1978) thinks authentic leadership is an integrated process and integrates the conflict and consistency between leaders and employees in terms of incentives and targets. Luthans \& avolio (2003) think authentic leadership is an integrating process of active ability and advanced organizational development, and promotes the leaders and employees to conduct active behaviors of higher self-awareness and self-regulation, thereby enhancing the active self-development. Walumbwa et al. (2008) further define it as a leading behavior pattern that can bring about a positive mental ability and moral atmosphere, and promote the formation of excellent self-awareness, internalized moral, balanced information processing and relational transparency during the interaction between leaders and employees.

2.2 Measuring tools

2.2.1Authentic leadership

With the authentic leadership scale compiled by Walumbwa et al., we adopted four dimensions and 16 questions: self-awareness, relational transparency, internalized moral and information balanced processing, which involved 4, 5, 4 and 3 questions, respectively. A Likert five-point scoring system was used, where 1-5 indicate Strongly disagree, Disagree, Unsure, Agree, and Strongly agree, respectively. The Cronbach's Alpha values of these four dimensions are 0.928, 0.886, 0.908 and 0.897, respectively, with an overall Cronbach's Alpha of 0.968.

2.2.2 Organizational citizen behaviors

The organizational citizen behavior scale including two dimensions of voice behavior and helping behavior was used (Dyne \& Lepine, 1998). The Cronbach's Alpha values of these two dimensions are 0.941 and 0.936, respectively, with an overall Cronbach's Alpha of 0.941.

\subsubsection{Workplace spirituality}

The workplace spirituality scale from Ke et al. (2014) is based on Milliiman's three-dimension scale of meaning at work, sense of community, and alignment with organizational values, and is China-specific. It has 27 questions. The Cronbach's Alpha values of these three dimensions are 0.937, 0.951 and 0.962, respectively, with an overall Cronbach's Alpha of 0.976.

2.3 Data processing and analysis

Data processing and statistical analysis were performed on SPSS 18.0 and Amos 17.0. (1) The variables of organizational citizen behavior and workplace spirituality over genders, age and education level were sent into independent sample t-tests. (2) Correlation analyses among authentic leadership, organizational citizen behavior and workplace spirituality were conducted. (3) Structural equation models were used to test the mediating role of workplace spirituality in between authentic leadership and organizational citizen behaviors. The organizational citizen behaviors and workplace spirituality were answered by subjective self-assessment, while authentic leadership was measured by a peer-assessed social distance method. Since self-assessment and peer assessment were both used here, the results were little affected by common method bias, which could be ignored.

\section{Results}

3.1Differences in organizational citizen behaviors and workplace spirituality between genders, among age groups, among education levels and among working years

Differences in organizational citizen behaviors and workplace spirituality between genders, among age groups, among education levels and among working years were assessed by independent 
sample t-tests. Results show organizational citizen behaviors are significantly different among ages and among working years. Specifically, more organizational citizen behaviors were conducted with the increase of age and working years. Workplace spirituality does not significantly differ between genders, ages, education levels, or working years.

Table 1 Descriptive statistics and correlation analysis

\begin{tabular}{|c|c|c|c|c|c|c|c|c|c|c|}
\hline & Mean & $\begin{array}{c}\text { Varianc } \\
\mathrm{e}\end{array}$ & 1 & 2 & 3 & 4 & 5 & 6 & 7 & 8 \\
\hline 1. Sex & 1.36 & .480 & & & & & & & & \\
\hline 2. Age & 2.38 & .927 & $.163^{*}$ & & & & & & & \\
\hline 3. Education & 1.64 & .617 & .073 & -.051 & & & & & & \\
\hline 4.Working years & 2.95 & 1.016 & $.215^{* *}$ & $.830^{* *}$ & -.049 & & & & & \\
\hline $\begin{array}{l}\text { 5. Working years together with } \\
\text { the current direct leader }\end{array}$ & 2.21 & .887 & .158 & $.543^{* *}$ & -.046 & $.573^{* *}$ & & & & \\
\hline 6. Authentic leadership & 3.7243 & .83396 & -.139 & -.034 & -.064 & -.052 & .085 & & & \\
\hline $\begin{array}{l}\text { 7. Organizational citizen } \\
\text { behavior }\end{array}$ & 4.0896 & .82149 & -.026 & $.189^{*}$ & -.009 & $.210^{*}$ & $.178^{*}$ & $.517^{* *}$ & & \\
\hline 8. Workplace spirituality & 3.8260 & .82830 & .045 & .105 & -.084 & .089 & .128 & $.567^{* *}$ & $.656^{* *}$ & \\
\hline
\end{tabular}

3.2Correlation analyses of authentic leadership, workplace spirituality and organizational citizen behaviors

Pearson differential correlation analysis shows that after control variables (gender, age, education level, working years, working years together with the current direct leader) were controlled, authentic leadership and its dimensions all significantly and positively affected voice behaviors and helping behaviors of employees (Tables 2, 3).

Table 2 Effects of authentic leadership on voice behaviors of employees

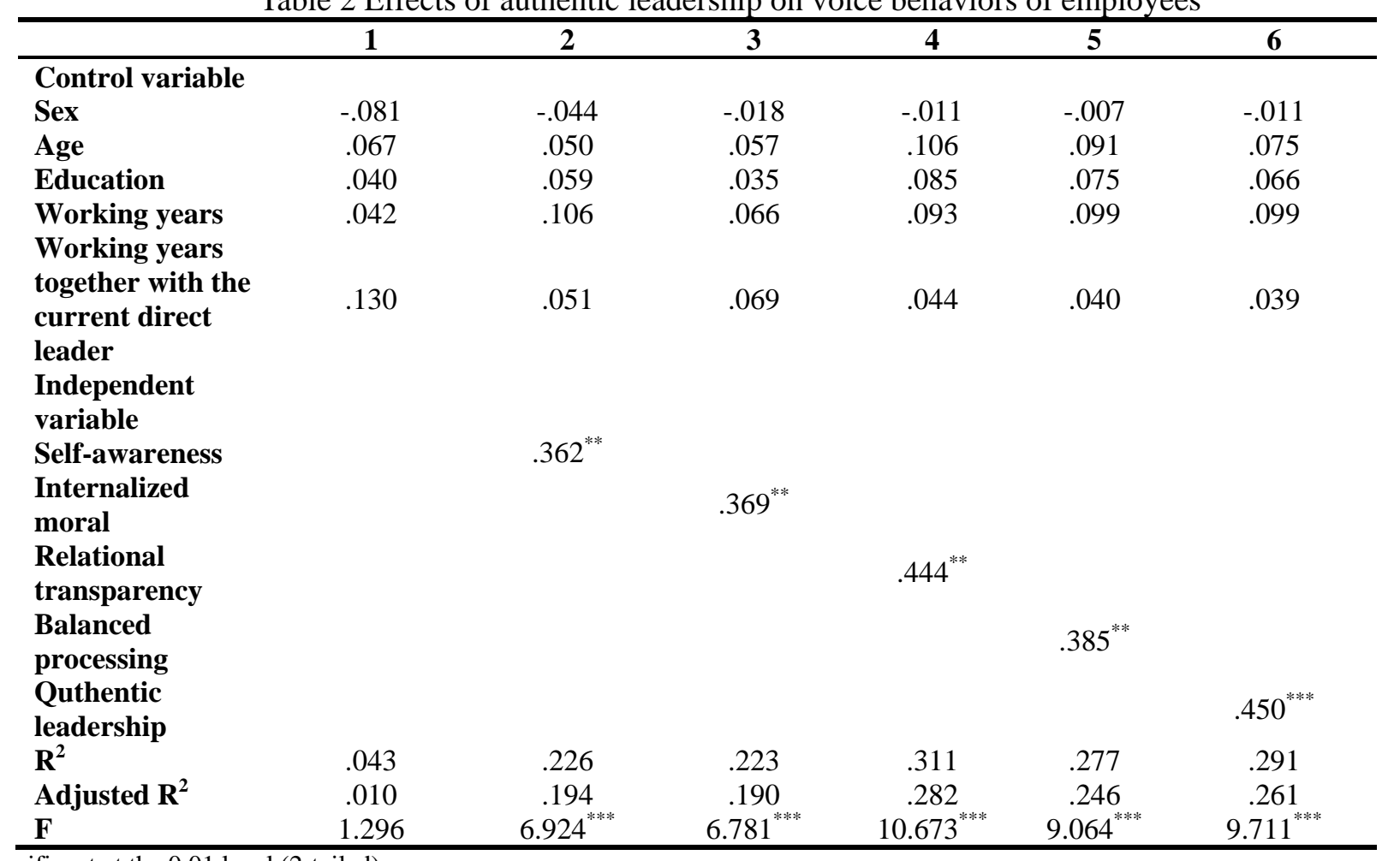

** significant at the 0.01 level (2-tailed).

*** significant at the 0.001 level (3-tailed).

Model 1 suggests that none of the control variables (gender, age, education level, working years, working years together with the current direct leader) significantly affect the voice behaviors of employees. In models 2 to 6 , the $\beta$ coefficients of self-awareness, internalized moral, relational transparency, balanced processing and authentic leadership are $0.362(\mathrm{p}<0.01), 0.369(\mathrm{p}<0.01)$, 
$0.444(\mathrm{p}<0.01), 0.385(\mathrm{p}<0.01)$ and $0.450(\mathrm{p}<0.001)$, respectively. After control variables (gender, age education level, working years together with the current direct leader) were controlled, authentic leadership and its dimensions all significantly \& positively affected the voice behaviors and helping behaviors of employees.

Table 3 Effects of authentic leadership on helping behaviors of employees

\begin{tabular}{|c|c|c|c|c|c|c|}
\hline & 7 & 8 & 9 & 10 & 11 & 12 \\
\hline \multicolumn{7}{|l|}{ Control variable } \\
\hline Sex & -.060 & -.029 & -.001 & -.001 & .006 & .001 \\
\hline Age & -.025 & -.039 & -.034 & .009 & -.003 & -.017 \\
\hline Education & -.025 & -.008 & -.029 & .014 & .007 & -.001 \\
\hline Working years & .248 & .302 & .270 & .291 & .300 & .298 \\
\hline Working years & & & & & & \\
\hline $\begin{array}{l}\text { together with the } \\
\text { current direct } \\
\text { leader }\end{array}$ & .026 & -.041 & -.031 & -.047 & -.055 & -.054 \\
\hline $\begin{array}{l}\text { Independent } \\
\text { variable }\end{array}$ & & & & & & \\
\hline Self-awareness & & $.370^{* *}$ & & & & \\
\hline internalized moral & & & $.402^{* *}$ & & & \\
\hline $\begin{array}{l}\text { relational } \\
\text { transparency }\end{array}$ & & & & $.453^{* * *}$ & & \\
\hline $\begin{array}{l}\text { balanced } \\
\text { processing }\end{array}$ & & & & & $.446^{* *}$ & \\
\hline $\begin{array}{l}\text { authentic } \\
\text { leadership }\end{array}$ & & & & & & $.449^{* *}$ \\
\hline $\mathbf{R}^{2}$ & .058 & .190 & .214 & .253 & .246 & .250 \\
\hline Adjusted $\mathbf{R}^{2}$ & .025 & .156 & .181 & .221 & .214 & .219 \\
\hline $\mathbf{F}$ & 1.751 & $5.544^{* * *}$ & $6.444^{* * *}$ & $8.012^{* * *}$ & $7.701^{* * *}$ & $7.910^{* * *}$ \\
\hline
\end{tabular}

Model 7 suggests that none of the control variables (gender, age, education level, working years, working years together with the current direct leader) significantly affect the helping behaviors of employees. In models 8 to 12 , the $\beta$ coefficients of self-awareness, internalized moral, relational transparency, balanced processing and authentic leadership are $0.370(\mathrm{p}<0.01), 0.402(\mathrm{p}<0.01)$, 0.453 ( $\mathrm{p}<0.001), 0.446(\mathrm{p}<0.01)$ and $0.449(\mathrm{p}<0.01)$, respectively. After control variables (gender, age education level, working years together with the current direct leader) were controlled, authentic leadership and its dimensions all significantly \& positively affected the voice behaviors of employees.

3.3workplace spirituality plays a mediating role between organizational citizen behaviors and authentic leadership

Structural equations were used to explore the action mechanism and influential route of authentic leadership on organizational citizen behaviors. The model fitting indices are showed in Table 4. The judgment criteria of different indices are: $\mathrm{X}^{2} / \mathrm{df}<5$, comparative fit index (CFI), Tucker-Lewis index (TLI), incremental fit index (IFI) all $>8$, and root mean square error of approximation (RMSEA) < 0.08, which all indicate good fitness. The results of goodness-of-fit index show that $\mathrm{X}^{2} / \mathrm{df}=3.149, \mathrm{RMSEA}=0.080, \mathrm{CFI}=0.979, \mathrm{TLI}=0.968$, and $\mathrm{IFI}=0.979$, indicating the good fitness of all indices (Fig. 2).

Results show that workplace spirituality plays mediating roles among self-awareness, internalized moral, relational transparency, balanced processing and helping behaviors.

Table 4 Structural equation model set

\begin{tabular}{cccccccc}
\hline$\chi^{2} / \mathrm{df}$ & RMSEA & GFI & NFI & RFI & IFI & TLI & CFI \\
\hline 3.149 & .080 & .945 & .970 & .954 & .979 & .968 & .979 \\
\hline
\end{tabular}




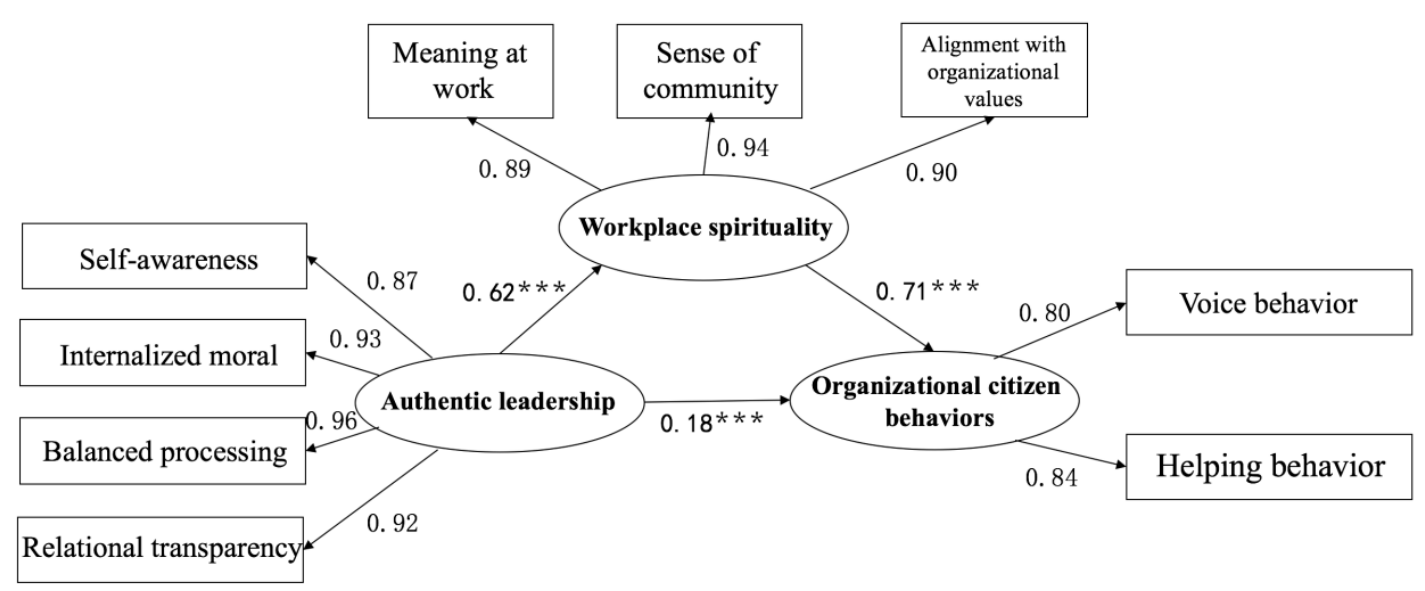

Fig. 2 Structural equation models

\section{Discussion}

The practice of modern management requests organizations should treasure the important roles of personnel, which demands not only the ability of properly treating personnel, but also paying attention to the driving factors, including inner spirits and emotion. Research on workplace spirituality is one manifestation of these demands. Exploration into the novel concept of workplace spirituality would enhance the organization and leaders to properly utilize the inner spiritual driving force of employees, and thereby further promote the personal and organizational performances.

\section{Reference}

[1] Xu Ying. Research on sincere leadership and organizational members' voice behavior [J]. Journal of Zhengzhou University of Light Industry, 2015, 16 (4): 29-33.

[2] Lv Yijing, Su Yong. Can sincere leadership break the silence of employees? A regulated mediation model [J]. psychology, 2015, 38 (5): 1178-1186.

[3]Ilies R, Morgeson F. P., Nahrgang J. D. Authentic Leadership and Eudaemonic Well Being:Understanding Leader Follower Outcomes [J].Leadership Quarterly, 2005, 16, 373-394.

[4]Avolio, B J, Gardner, WL, Walumbwa F O, Luthans F, and May D R. Unlocking themask:A look 15:801-823 at the process by which Authentic Leaders impact follower attitudes and behaviors [J]. Leadership Quarterly.2004

[5]Fred O. Walumbwa, Peng Wangb, Hui Wangc, John Schaubroeckd, Bruce J. Avolio.. Psychological processes linking authentic leadership to follower behaviors [J]. The Leadership Quarterly, 2010, 901-914.

[6] Wang Wenjuan. Review and Prospect of organizational citizenship behavior [J]. social psychology science, 2011, 26 (11-12): 1042-1047.

[7]Ahmad A, Omar Z. Improving Organizational Citizenship Behavior through Spirituality and Work Engagement[J]. American Journal of Applied Sciences, 2015, 3 (12): 200-207.

[8] Ke Jiang Lin, Wang Juan, fan Liqun. Workplace mentality research progress and Prospect of [J]. East China economic management, 2015, 29 (2): 149-157.

[9]Kazemipour, Farahnaz, Amin, etal. Relationship Between Workplace Spirituality and Organizational Citizenship Behavior Among Nurses Through Mediation of Affect[J]. Journal of Nursing Scholarship, 2012, 44 (3): 302-310.

[10], Zhang Zhipeng, and Ping. New frontiers of management research abroad research on workplace spirituality: [J]. foreign economy and management, 2012, 34 (11): 61-71. 
[11]Burack E. Spirituality in the workplace[J]. Journal of Organizational Change Management, 1999, 4 (14): 280-291.

[12]Podsakoff P M, Ahearne M, Mackenzie S B. Organizational citizenship behavior and the quantity and quality of work group performance[J]. Journal of Applied Psychology, 1998 (2): 262-270.

[13]Farh, L J, Zhong C B, etal. Organizational Citizenship Behavior in the People's Republic of China[J]. Organization Science, 2004, 15 (2): 241-253.

[14]Walumbwa, F O, Avolio, etal. Authentic leadership: Development and validation of a theory-based measure[J]. Journal of Management, 2008, 34 (1): 89-126.

[15] Ke Jiang Lin, Sun Jianmin, Wang Juan. Development and reliability and validity test of workplace mental strength scale [J]. Chinese Journal of clinical psychology, 2014, 22 (5): 826-830.

[16]Ashmos D P, Duchon D. Spirituality at work: A conceptualization and measure[J]. Journal of Management Inquiry, 2000 (9): 134-145.

[17]Milliman J, AJ C, Ferguson J. Workplace spirituality and employee work attitudes: An exploratory empirical assessment[J]. Journal of Organizational Change Management, 2003, 16 (4): 426-447.

[18]Duchon D, Plowman D A. Nurturing the Spirit at Work: Impact on Work Unit Performance[J]. The Leadership Quarterly, 2005, 16 (5): 807-833.

[19]Dyne, V L, Lepine, etal. Helping and Voice Extra-Role Behavior: Evidence of Construct and Predictive Validity[J]. Academy of Management Journal, 1998, 41 (1): 108-119. 